\title{
Let the patient revolution begin
}

\author{
Patients can improve healthcare: it's time to take partnership seriously
}

\author{
Tessa Richards analysis editor ${ }^{1}$, Victor M Montori professor ${ }^{2}$, Fiona Godlee editor in chief $^{1}$, Peter \\ Lapsley patient editor ${ }^{1}$, Dave Paul secretary of the patient advisory group ${ }^{2}$
}

'BMJ, London WC1H 9JR, UK; ${ }^{2}$ Knowledge and Evaluation Research (KER) Unit, Mayo Clinic, Rochester, MN, USA

\begin{abstract}
A hundred years ago George Bernard Shaw lambasted the medical profession as a conspiracy against the laity. ${ }^{1}$ Today, disease and doctor centric health systems that are costly, wasteful, fragmented, and too often uncaring are provoking similar ire. ${ }^{2}$
\end{abstract}

Despite the best intentions and undoubted skill of many who work within healthcare, access to care, and its quality, vary markedly, and most people in rich countries access a confusing smorgasbord of tests and treatments whose merits are hyped and harms underplayed. ${ }^{3}$ Patients lack information on practice variation, the effectiveness of their care, and the extent of medical uncertainty. Practice is informed by an incomplete research base bedevilled with selection and reporting bias, ${ }^{4}$ and at worst fraud. The preservation of institutional bureaucracies, as well as professional and commercial vested interests, have consistently trumped the interests of patients. The healthcare industrial complex stands accused of losing its moral purpose. ${ }^{5}$ This corruption in the mission of healthcare requires urgent correction. And how better to do this than to enlist the help of those whom the system is supposed to serve-patients? Far more than clinicians, patients understand the realities of their condition, the impact of disease and its treatment on their lives, and how services could be better designed to help them. ${ }^{6}$

Clinicians and patients need to work in partnership if we are to improve healthcare and challenge deeply ingrained practices and behaviours. Doing this won't be easy for either side after eons of paternalism, and some patients may continue to prefer their doctor to take the lead role in decision making. But good examples are showing the way. The Choosing Wisely initiative in the US (www.choosingwisely.org/) brings patients and doctors together to identify and reduce the use of unwarranted and ineffective interventions. Discussion groups of patients, carers, and clinicians led by the James Lind Alliance in the United Kingdom, and the Patient Centered Outcomes Research Institute in the United States, are shedding light on the mismatch between the questions that patients and doctors want answers to and the ones that researchers are investigating. Joint discussions have helped build a database of uncertainties about the effects of treatment (www.library.nhs.uk/duets/).
Patients and doctors are also collaborating to design new services and information systems. ${ }^{7}$ Leaders in innovative partnership include ReshapeHealth (www.radboudreshapecenter. com), which is pioneering patient led and "crowdfunded" research. A growing number of healthcare organisations are giving patients access to, and in some cases control over, their medical records. ${ }^{7}$ At the Mayo Clinic a free app gives patients full access to their medical notes, pathology reports, and radiology reports; and because a shift in power depends on establishing a common lexicon, work is under way to reduce the medical jargon in these resources. There are guides on why and how to engage with patients (http://epatientdave.com/letpatients-help/ $),{ }^{8}$ and some patients are already acting as "sherpas" to promote joint working, ${ }^{6}$ including members of the participatory medicine movement (http://participatorymedicine. org).

Online patient communities where patients meet, talk, support, inform, and coach each other are empowering patients (although it is important to note who sponsors them). ${ }^{9}$ They also provide a rich and as yet largely untapped learning resource for health professionals. Examples include healthunlocked.com, healthtalkonline, rawarrior.com, and cancergrace.org (www. bmj.com/podcast/2013/04/29/dying-patients-hospital-e-patientsonline). There are salutary lessons in the gulf between conversations in the clinic and the concerns patients share with their peers.

Advocacy for patient engagement in the US, UK, mainland Europe, and well beyond is driven largely by the belief, backed by some evidence, that engaging patients will reduce healthcare costs through the avoidance of unnecessary investigation and treatment. Patient engagement is seen as a way to help health systems become sustainable. Some have argued that it is the "blockbuster drug of the century" and will deliver equivalent dividends. ${ }^{10}$

But partnering with patients must be seen as far more than the latest route to healthcare efficiency. It's about a fundamental shift in the power structure in healthcare and a renewed focus on the core mission of health systems. We need to accept that expertise in health and illness lies outside as much as inside 
medical circles and that working alongside patients, their families, local communities, civil society organisations, and experts in other sectors is essential to improving health. Revolution requires joint participation in the design and implementation of new policies, systems, and services, as well as in clinical decision making.

Much remains to be discovered, evaluated, and implemented to achieve meaningful partnership with patients. There is also a need to embed shared decision making, based on individual patients' preferences ${ }^{11}$ and goals, ${ }^{12}$ into routine practice. At an open meeting in June in Peru (www.isdm2013.org), which can be followed through social media, the shared decision making community will further global debate on the latest thinking and research.

For its part the $B M J$ is stepping up its commitment to patient partnership. We already have an online collection of articles on shared decision making and a growing library of patient journey articles. ${ }^{13}$ Now we want to develop a strategy for patient partnership that will be reflected across the entire journal. We plan to establish a panel of patients and clinicians to help us with this work and will report back on our progress.

It has been said that healthcare won't get better until patients play a leading role in fixing it. ${ }^{14} \mathrm{We}$ agree and look forward to helping drive the patient revolution on.
Competing interests: We have read and understood the BMJ Group policy on declaration of interests and declare the following interests: $\mathrm{FG}, \mathrm{TR}, \mathrm{PL}$, and $\mathrm{DP}$ have none; VMM is chair of the organising committee, 7th International Shared Decision Making Conference, Lima, Peru.

Provenance and peer review: Commissioned; not externally peer reviewed.

1 Shaw GB. The doctor's dilemma: a tragedy. 1st World Library.

Fung B. How the US health-care system wastes $\$ 750$ billion annually. Atlantic 2012 Sept 7. www.theatlantic.com/health/archive/2012/09/how-the-us-health-care-system-wastes750billionannually/262106/.

3 Moynihan R, Glaziou P, Woloshin S, Schwartz L, Santa J, Godlee G. Winding back the harms of too much medicine. BMJ 2013;346:f1271.

4 Chalmers I, Glaziou P. Avoidable waste in the production and reporting of research evidence. Lancet 2009;374;86-9.

5 Smythe C. NHS urged to find its "moral purpose." Times 2013 March 8. www.thetimes. co.uk/tto/health/news/article3708313.ece.

6 Young K. Doctors' understanding of rheumatoid disease does not align with patients' experiences. BMJ 2013;346:22901.

7 Davies P. Should patients be able to control their own records? BMJ 2012;345:e4905. Coulter A. Engaging patients in healthcare. Open University Press, 2011.

De Bronkart D. How the e-patient community helped save my life. BMJ 2013;346:f1990. 10 Dentzer S. Rx for the "blockbuster drug" of patient engagement. Health Affairs 2013;32:202

11 Mulley A, Trimble C, Elwy G. Stop the silent misdiagnosis: patient preferences matter. BMJ 2012;345:e6572.

12 Roland M, Paddison C. Better management of patients with multimorbidity. BMJ 2013;346: $: 2510$.

13 Lapsley P. Lessons from patient journeys. BMJ 2013;346:f1988.

14 Hadler NM. The citizen patient. University of North Carolina Press, 2013.

Cite this as: BMJ 2013;346:f2614

๑ BMJ Publishing Group Ltd 2013 